\title{
Improvement in Performance of Shaped Charge using Bimetallic Liner
}

\author{
Santosh N. Ingole ${ }^{1, a,{ }^{*}}$, M.J. Rathod ${ }^{2, b}$, K.M. Rajan ${ }^{3, c}$, R.K. Sinha ${ }^{4, d}$, S.K. Nayak ${ }^{3, e}$, \\ Nair Prakash N.P. ${ }^{3, f}$, V.K. Dixit ${ }^{3,9}$, S.G. Kulkarni ${ }^{5, h}$ \\ ${ }^{1}$ Directorate General Aeronautical Quality Assurance, Ministry of Defence, New Delhi- 110011, \\ India \\ ${ }^{2}$ College of Engineering Pune, Shivajinagar, Pune- 411005, India \\ ${ }^{3}$ Defence Research and Development Organisation, Armament Research and Development \\ Establishment Pashan, Pune- 411021, India \\ ${ }^{4}$ Defence Research and Development Organisation, High Energy Materials Research Laboratory \\ Sutarwadi, Pune- 411021, India \\ ${ }^{5}$ Defence Intitute of Advanced Technology Girinagar, Pune - 411025, India

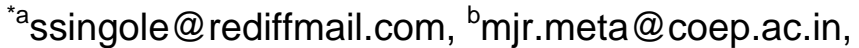 \\ cdirector@arde.drdo.in, ${ }^{\mathrm{d}} \mathrm{rksinha@hemrl.drdo.in,}{ }^{\mathrm{e}}$ sknayak@arde.drdo.in,,nairprakash@arde.drdo.in, \\ gvkdixit05@rediffmail.com, ${ }^{\mathrm{h}}$ sgkulkarni@diat.ac.in
}

Keywords: Bimetallic Liner, Monolithic Liner, Penetration Depth, Tip Velocity, Slug Velocity

Abstract. Shaped charge has been designed by replacing conventional monolithic liner with bimetallic liner to possibly enhance its penetration capability. A shaped charge with bimetallic liner formulated using aluminum as the outer cone and copper as the inner cone with cone angle of $52^{0}$, liner thickness of $2.4 \mathrm{~mm}$ and calibre of $60 \mathrm{~mm}$. Theoretically predicted performance parameters have been compared with that of experimentally determined such as penetration depth and jet tip / slug velocity. The experimental results are reasonably in good agreement with theoretically predicted values. Penetration depth and tip velocity exhibit $22.5 \%$ and $10.67 \%$ increase respectively in comparison with shaped charge using copper as monolithic liner.

\section{Introduction}

Metallic lined shaped charge is frequently used in anti-armour projectiles for their higher penetration capabilities due to high velocity homogenous and unbroken jet formed after collapse of metallic liner by explosive action on the conical cavity of the projectile. The jet velocity is dependent upon several factors such as explosive used in the projectile, liner material, its density and liner thickness, cone angle, base of conical cavity, L/D ratio of the projectile, etc. [1].

Penetrative performance depends on cone angle as well. Smaller the cone angle $\left(\sim 40^{0}\right)$, narrower will be the jet and deeper will be the penetration. However, for higher lethality cone angle can be increased up to $120^{\circ}$. Most of the High Explosive Anti-tank (HEAT) weapons presently being used are based on monolithic liner [2,3].

Attempts have been made by various researchers to improve the penetrative performance of shaped charge weapon by modifying the existing configuration. Replacement of monolithic liner with bimetallic liner is one of the preferred options for enhancement of performance of such weapon. Number of workers have reported bimetallic liner based shaped charge weapons using high density and high valued metals such as Au, Pt, Rh, Ta etc.[4]. Skolnick and Goodman [5] have elaborately discussed specific advantages for using multi-layered liners in combination with 
different explosives in regards to enhancement of performance and also offered possible mechanism.

Chanteret et al [6] reported combination of two different liner materials, one with high sound velocity and other with high ductility, in designing the shaped charge. According to these authors, high tip velocity is controlled by the material having higher sonic velocity and supported by the material having high ductility.

In the present study, attempts have been made to improve penetrative performance by replacing monolithic liner with bimetallic liner consisting of aluminum (outer cone) and copper (inner cone). Theoretical prediction of the performance parameters for configured shaped charge has been carried out by computer simulation using hydrocode (AutoDYN) [7]. The theoretically predicted parameters have been experimentally validated and results are compared.

\section{Experimental Section}

\section{Materials and methods}

Materials and configuration of bimetallic liner shaped charge

The configuration details of bimetallic liner shaped charge (BMLSC) are summarized in Table 1:

Table 1: Configuration of BMLSC.

\begin{tabular}{|l|l|l|}
\hline Nomenclature & Particulars & Remarks \\
\hline Calibre & $60 \mathrm{~mm}$ & \\
\hline Length & $115 \mathrm{~mm}$ & $\mathrm{~L} / \mathrm{D} 2$ \\
\hline Main Charge & HMX-Wax & $\rho=1.758 \mathrm{~g} / \mathrm{cm}^{3}, 380 \mathrm{~g}$ \\
\hline Booster & RDX-Wax & $\rho=1.685 \mathrm{~g} / \mathrm{cm}^{3}, 10 \mathrm{~g}$ \\
\hline Liner Material (L1) & Copper & $1.2 \mathrm{~mm} \mathrm{flow} \mathrm{formed} 52^{0}, 54 \mathrm{~mm}$ \\
\hline Liner Material (L2) & Aluminum & $\begin{array}{l}1.2 \mathrm{~mm} \mathrm{flow} \mathrm{formed} 52^{0}, 54 \mathrm{~mm} \\
\text { long }\end{array}$ \\
\hline Case Material for shaped charge & Aluminum alloy & Material as per HE-30 standard \\
\hline
\end{tabular}

General configuration of typical BMLSC is given in figure 1.

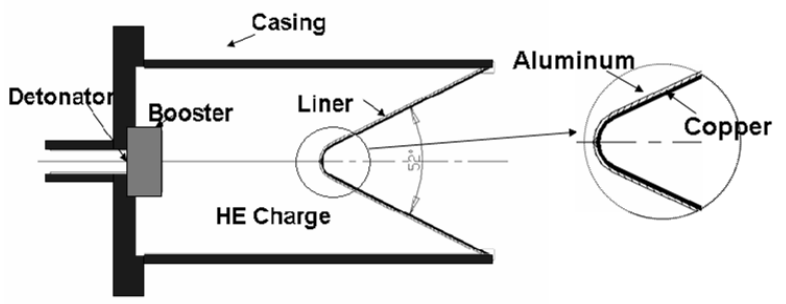

Figure 1. General configuration of BMLSC.

\section{Methods}

\section{(A) Theoretical prediction of performance parameters by computer simulation.}

BMLSC was modelled using nonlinear hydrocode-AutoDYN [8] assuming axial symmetry as it reduces computational time. The Aluminum and copper were used in different weight proportions (Al:Cu::45:55; 50:50; 55-45; 85:15) keeping the effective liner thickness as $2.4 \mathrm{~mm}$. Similar studies were also carried out for monolithic liner shaped charge (MLSC) consisting of copper as liner material for comparison. The penetration depth was predicted with mild steel target plates to 
understand the penetration behaviour of BMLSC. The simulation results include the penetration depth and tip velocity for MLSC and BMLSC.

\section{(B) Experimental evaluation}

MLSC (Cu) and BMLSC (Al:Cu::50:50) have been fabricated as per the details included under methods. They were subjected to penetration and soft recovery trials. Jet parameters were determined by flash radiographic technique. Details of each experimental technique are included in the following sub-sections.

\section{Penetration trial}

Penetration depth of shaped charge was measured at standoff distance of 5 calibre in mild steel target plates stacked in vertical orientation to ascertain the penetration behaviour of BMLSC.. The test setup for penetration trial is given in Figure 2. Prediction of penetration depth was made under identical condition as in computer simulation.

\section{Soft recovery trial}

Recovery of shaped charge jet and slug particles were done in the experimental setup as described by Lassila et al [9]. Figure 3 includes the test setup used in the trial.

Various materials with increasing density such as air, aqueous film forming foam (AFFF), polystyrene (PS or Thermocole), polyethylene foam (PEF); polyurethane foam (PUF); high density polyurethane (HDPUF) and water were used in the test setup to capture jet/slug particles. The recovered jet and slug particles were subjected to metallographic investigations.

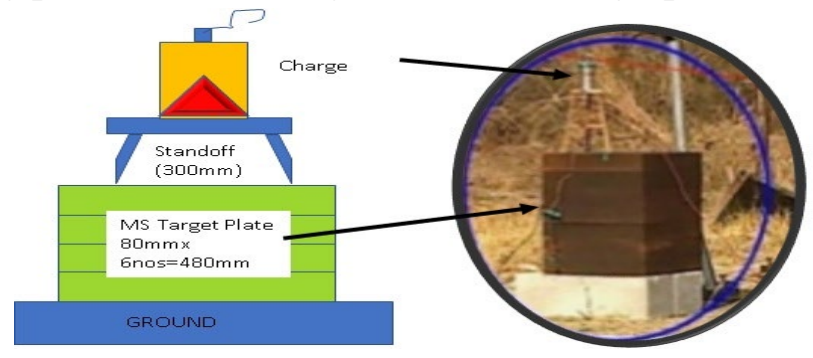

Figure 2. Test setup for penetration trials

\section{Flash radiography $(F X R)$}

FXR technique was used to record liner collapse of cone, jet formation, jet penetration, and slug formation. Synchronization pattern / schematic setup is depicted in figure 4. The velocity, dimension and breakup time of jet were calculated from FXR records. The FXR records experimentally obtained and predicted by computer simulation are included in figure 5.

\section{Results and Discussion}

\section{Mechanism of jet formation in BMLSC}

Figure 6 shows the collapse mechanism of liner and jet formation at different time intervals assuming the complete collapse and formation of fully emerged jet after several microseconds. 
(a)

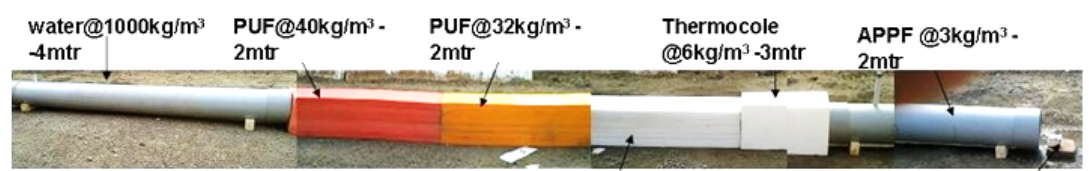

(b)

PEF@15kg/m³ $-2 \mathrm{mtr}$

\begin{tabular}{|c|c|c|c|}
\hline $\begin{array}{c}\text { WATER } \\
4 \mathrm{~m}\end{array}$ & $\begin{array}{c}\text { PUF } 2 \mathrm{~m} \\
\rho=40 \\
\mathrm{~kg} / \mathrm{m}^{3}\end{array}$ & $\begin{array}{c}\text { PUF } 2 \mathrm{~m} \\
\rho=32 \\
\mathrm{~kg} / \mathrm{m}^{3}\end{array}$ & $\begin{array}{c}\text { PEF } 2 \mathrm{~m} \\
\rho=16 \\
\mathrm{~kg} / \mathrm{m}^{3}\end{array}$ \\
\hline
\end{tabular}

Charge + Standoff(180mm) Charge

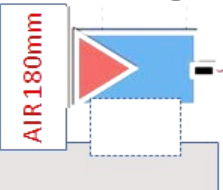

Figure 3. (a) Experimental set up and (b) Plan for soft recovery trial.

(a)

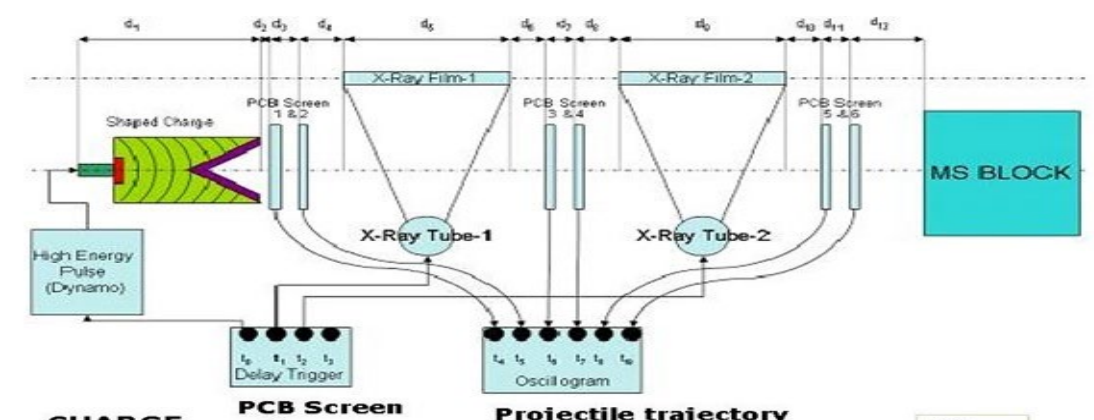

(b)

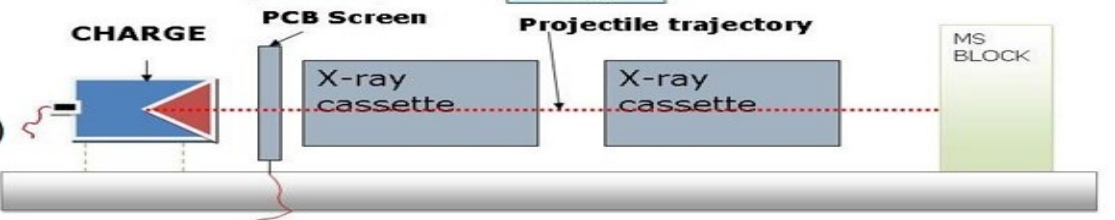

Figure4. (a) Synchronisation plan; (b) Schematic setup for flash radiography.

(a)
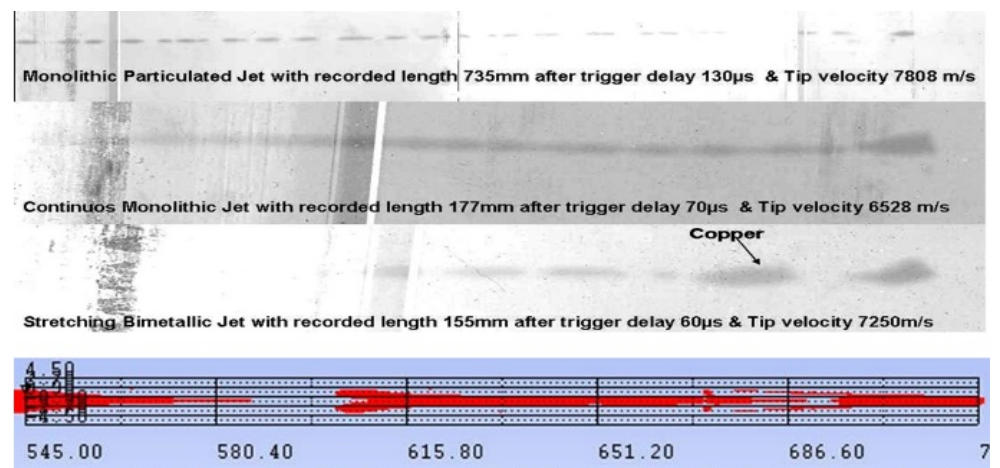

(b)

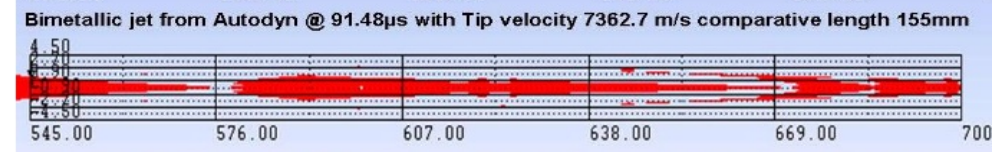

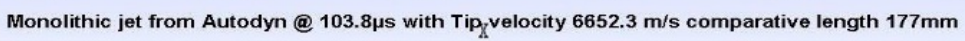

Figure 5. (a) FXR of jets; (b) comparative jet from computer simulation.

From figure 6, it is clear that for 50:50 BMLSC configuration, maximum portion of liner of inner cone constitutes the jet whereas maximum portion of liner of outer cone constitutes the slug. It is evident that depth of penetration is directly proportional to length of unbroken jet and under root of density of jet material and inversely proportional to under root density of target material. Thus, for better penetrative performance high density jet material is preferred. This is applicable to MLSC with copper as the liner material. In BMLSC, the low-density material like aluminum remains in 
slug and subsequently vaporizes out. Copper has higher density $\left(8.9 \mathrm{~g} / \mathrm{cm}^{3}\right)$ and melting point $\left(1083^{0} \mathrm{C}\right)$ than aluminum (density: $2.71 \mathrm{~g} / \mathrm{cm}^{3}$ and melting point: $657^{0} \mathrm{C}$ ) is preferred material for shaped charge application [10]. The sonic velocity of aluminum $(6.4 \mathrm{~km} / \mathrm{s})$ is, however, higher than copper $(4.7 \mathrm{~km} / \mathrm{s})$. In 50:50 configuration of BMLSC, the high-density material like copper constitutes only $50 \%$ of mass, but still exhibits improved penetrative performance mostly because aluminum accelerates the jet formation process. Jet contains more quantity of copper than aluminum and helps to get improved performance as per conservation of energy and momentum principles. The inner part of the bimetallic cone (which is not in contact with explosive) forms jet, which is squeezed out from the apex of inner cone while outer cone (in contact with explosive) moves slower with respect to the inner cone and forms residue in the form of slug. Thus, the metal in the conical liner divides in two parts of velocity gradient with reference to the location. Simulation results from the extant work confirm this hypothesis and justifies the use of bimetallic liner for improvement in penetrative performance.

\section{Penetration trial}

Table 2 includes the results of penetration trials.

Table 2. Depth of penetration determined from experiments

\begin{tabular}{|c|l|l|l|}
\hline Charge & Configuration & Penetration(mm) & Remarks \\
\hline A-5 & Monolithic (Cu) & 190 & $\begin{array}{l}\text { BMLSC exhibits improved } \\
\text { penetration depth over } \\
\text { MLSC }\end{array}$ \\
\hline A-1 & BiMetallic (Al:Cu::50:50) & 220 & \\
\hline
\end{tabular}

\section{Soft recovery trials}

Jet and slug particles recovered during the trials were subjected to metallographic investigation. Figure 7 shows the jet and slug material recovered during the experimental trial along with that obtained from computer simulation. From this figure; cut section of the slug, it is clear that outer cone encases the inner one. It is in line with the prediction made in computer simulation studies. Further, slug recovered from bimetallic liner has mass 19.25g against total liner mass of $94.10 \mathrm{~g}$ which implies that the slug is only $20.45 \%$ of total liner mass and Al has been vaporized out with visible thin layer of $\mathrm{Al}-\mathrm{Cu}$ alloy (duralumin) at certain places. Metallography of recovered slug reveals recrystallized grain structure, due to melting and realigning in the direction of flow of jet. Cut section of slug from BMLSC do not show any trace of $\mathrm{Al}$ or alloy of $\mathrm{Al}-\mathrm{Cu}$ formed inside the core, thus indicating the vaporization of aluminum due to its lower melting point. However, outer portion of the slug exhibits formation of Al-Cu alloy on the surface due to interaction of both the metals at high temperature. Hardness of both the recovered slugs of BMLSC and MLSC remains in the same range viz.,48-65 BHN in monolithic and 54-58 BHN in bimetallic.

\section{Flash radiography $(\mathrm{FXR})$}

Results from FXR records are presented in Table 3. Exposed jet is shown in figure 5 with comparative picture from computer simulation. 


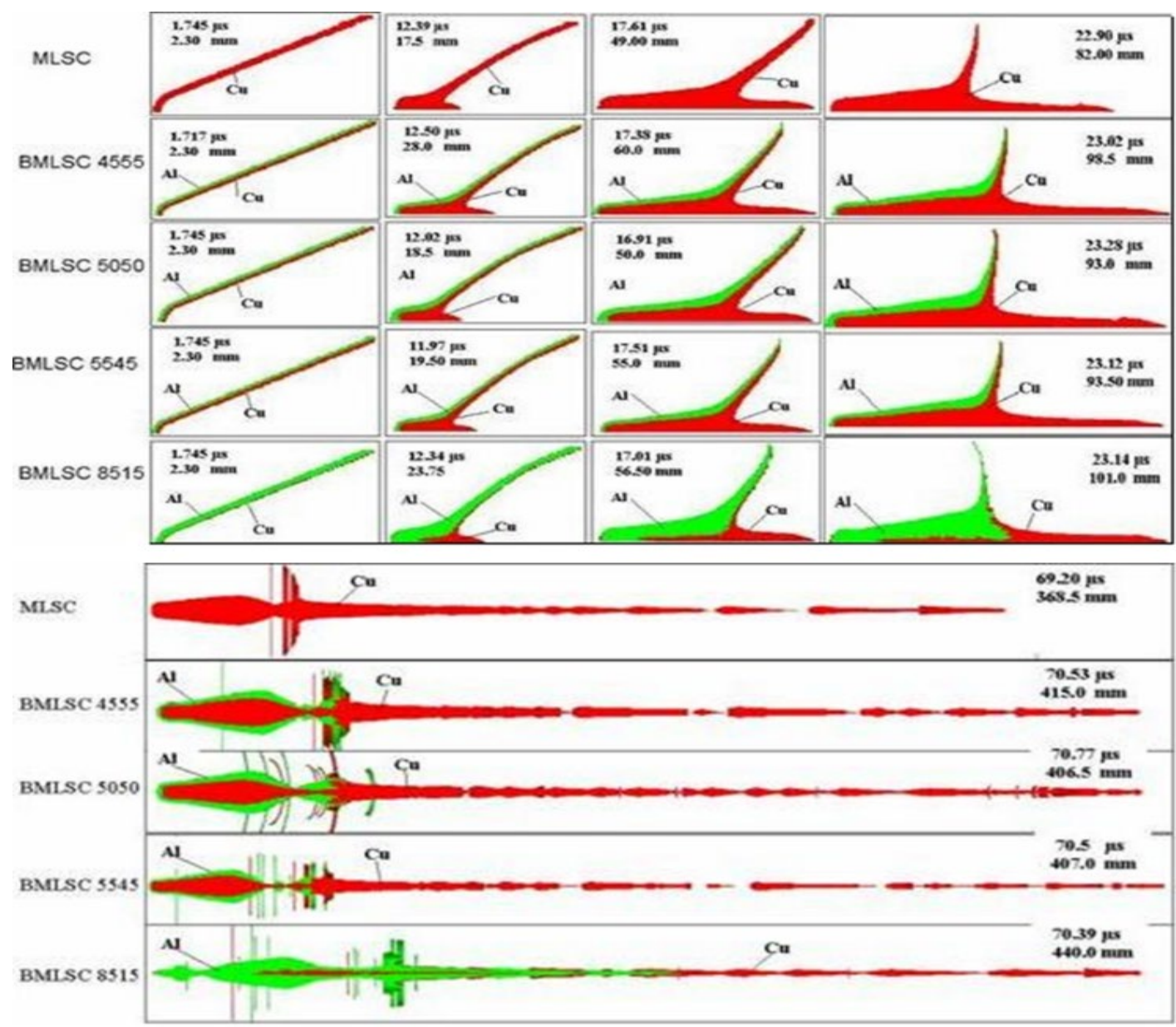

Figure 6. Liner collapse at various time intervals for different configurations.

Table 3: Results from flash radiography.

\begin{tabular}{|c|c|c|c|}
\hline Charge & Configuration & Parameters & Observations \\
\hline$A-2$ & Monolithic(Cu) & $\begin{array}{l}\text { Triggering delay T1- } \\
130 \mu \mathrm{s} \& \mathrm{~T} 2-300 \mu \mathrm{s}\end{array}$ & $\begin{array}{l}\text { Jet length recorded is } 674 \mathrm{~mm} \text { and jet tip } \\
\text { velocity at trigger delay of } 130 \mu \text { s is } 7832 \mathrm{~m} / \mathrm{s}\end{array}$ \\
\hline A-7 & Monolithic(Cu) & 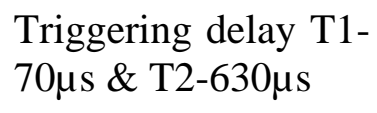 & $\begin{array}{l}\text { Jet length recorded is } 177 \mathrm{~mm} \text { and jet tip } \\
\text { velocity at trigger delay of } 70 \mu \mathrm{s} \text { is } 6528 \mathrm{~m} / \mathrm{s}\end{array}$ \\
\hline$A-3$ & $\begin{array}{l}\text { BiMetallic } \\
\text { (Al:Cu::50:50) }\end{array}$ & $\begin{array}{l}\text { Triggering delay T1- } \\
60 \mu \mathrm{s} \& \mathrm{~T} 2-430 \mu \mathrm{s}\end{array}$ & $\begin{array}{l}\text { Jet length recorded is } 155 \mathrm{~mm} \text { and jet tip } \\
\text { velocity at trigger delay of } 60 \mu \mathrm{s} \text { is } 7250 \mathrm{~m} / \mathrm{s}\end{array}$ \\
\hline
\end{tabular}

The results of penetrative performance based on computer simulation studies and experimental evaluation on are presented in Table 4. The error in computer simulation owes due to material characteristics. However, all the results are comparable from BMLSC and MLSC tested against standard conditions. 


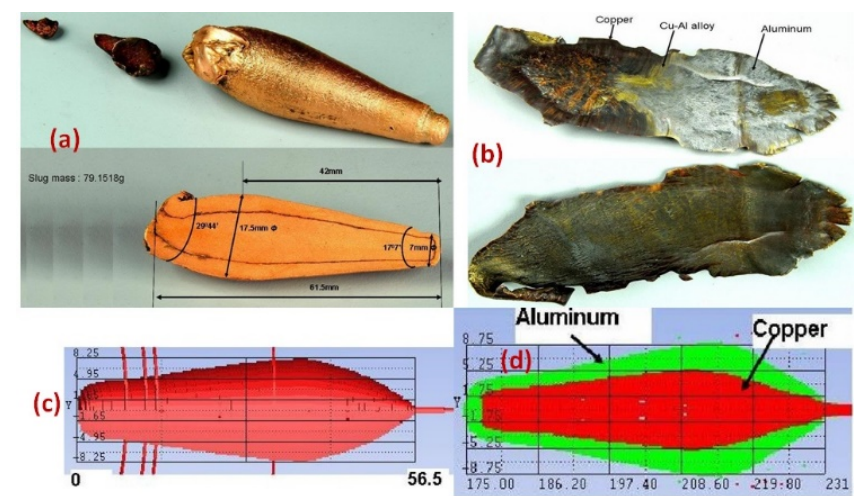

Figure 7. (a) MLSC jet/slug particle ; (b) BMLSC slug; (c) slug for MLSC from computer simulation and (d) slug for BMLSC from computer simulation

Table 4:Penetrative performance results based on computer simulation studies and experimental evaluation.

\begin{tabular}{|l|l|l|l|l|}
\hline Configuration & \multicolumn{4}{|c|}{ Result Comparison } \\
\cline { 2 - 5 } & $\begin{array}{l}\text { Performance } \\
\text { Parameter }\end{array}$ & $\begin{array}{l}\text { Computer } \\
\text { simulation }\end{array}$ & $\begin{array}{l}\text { Experimental } \\
\text { evaluation }\end{array}$ & $\begin{array}{l}\text { Remarks } \\
\text { (error) }\end{array}$ \\
\hline \multirow{2}{*}{ MLSC (Cu) } & Penetration depth & $310 \mathrm{~mm}$ & $190 \mathrm{~mm}$ & $64 \%$ \\
\cline { 2 - 5 } & Tip velocity at $70 \mu \mathrm{s}$ & $6652 \mathrm{~m} / \mathrm{s}$ & $6528 \mathrm{~m} / \mathrm{s}$ & $2 \%$ \\
\cline { 2 - 5 } & $\begin{array}{l}\text { Slug mass to original } \\
\text { mass \% }\end{array}$ & - & $58.85 \%$ & - \\
\hline \multirow{2}{*}{$\begin{array}{l}\text { BMLSC } \\
\text { Al:Cu::50:50) }\end{array}$} & Penetration depth & $380 \mathrm{~mm}$ & $220 \mathrm{~mm}$ & $72 \%$ \\
\cline { 2 - 5 } & Tip velocity at $60 \mu \mathrm{s}$ & $7362 \mathrm{~m} / \mathrm{s}$ & $7250 \mathrm{~m} / \mathrm{s}$ & $1.5 \%$ \\
\cline { 2 - 5 } $\begin{array}{l}\text { MLSC vs } \\
\text { BMLSC }\end{array}$ & $\begin{array}{l}\text { Slug mass to original } \\
\text { mass \% }\end{array}$ & - & $20.45 \%$ & - \\
\cline { 2 - 5 } & Penetration depth & $\begin{array}{l}\text { Increaed by } \\
22.58 \%\end{array}$ & $\begin{array}{l}\text { Increaed by } \\
15.79 \%\end{array}$ & $\begin{array}{l}\text { Difference is } \\
\text { comparable }\end{array}$ \\
\cline { 2 - 5 } & Tip velocity at $70 \mu \mathrm{s}$ & $\begin{array}{l}\text { Increased by } \\
10.67 \%\end{array}$ & $\begin{array}{l}\text { Increased by } \\
11.06 \%\end{array}$ & \\
\cline { 2 - 5 } & $\begin{array}{l}\text { Slug mass to original } \\
\text { mass \% }\end{array}$ & - & $\begin{array}{l}\text { Decreased by } \\
65.25 \%\end{array}$ & $\begin{array}{l}\text { Substantial } \\
\text { difference }\end{array}$ \\
\hline
\end{tabular}

\section{Conclusion}

Based on the results obtained from the computer simulation studies and limited experimental trials, it can be concluded that bimetallic liner shaped charge exhibits better penetrative performance than monolithic liner shaped charge.

It was also realized from the studies, that the liner of the outer cone (aluminium) in BMLSC configuration mostly goes in the slug, a large portion of it vaporizes out, whereas, liner of the inner cone (copper) mostly constitutes the jet.

The study can be further extended to design shaped charges for more effective anti-tank ammunitions and oil-well perforation with increased performance.

\section{Symbols and Abbreviations}

BMLSC : $\quad$ Bimetallic liner shaped charge

MLSC : $\quad$ Monolithic liner shaped charge

HEAT : High explosive anti-tank

$\rho \quad$ : density 


\section{Acknowledgements}

We acknowledge Director General, DGAQA New Delhi; Director-College of Engineering,Pune; Director-Armament Research and Development Establishment Pune; Director-High Energy Materials Research Laboratory Pune and Vice Chancellor-Defence Institute of Advanced Technology Pune for their wholehearted support and constant encouragement in the present work.

\section{References}

[1] Ernest L Baker, Modeling and optimization of shaped charge liner collapse ad jet formation, Technical Report ARAED-TR-92019, US Army Research Development and Engineering Center, New Jersey USA, 1993.

[2] Robert A Brimmer, Manual for shaped charge design, Report 1248, US Naval Ordnance Test Station China Lake, CA, USA, 1950.

[3] WP Walters and SK Golaski, Hemispherical and conical shaped-charge liner collapse and jet formation, Report BRL-TR-2781, US Army Ballistic Research Laboratory Aberdeen Proving Ground, Maryland, USA, 1987.

[4] David Hasenberg, Consequences of coaxial jet penetration performance and shaped charge design criteria, Thesis - NPS-PH-10-0010, Naval Postgraduate School, CA, USA , 2010.

[5] Saul Skolnick and Albert Goodman, Energy transfer through a multi-layer liner for shaped charges, US Patent 4498367, Southwest Energy Group Ltd Albequerque N Mex, 1985.

[6] P.Y. Chanteret and A. Lichtenberger, Bimetallic liners and coherence of shaped charge jets, Proc. $15^{\text {th }}$ International Symposium on Ballistics, Jerusalem, Israel, 21-24 May 1995, p.143.

[7] Marinko Ugrcic and Dušan Ugrcic, FEM Techniques in Shaped Charge Simulation, Scientific Technical Review ,2009, LVIX ,1, 26-33.

[8] Autodyn User Manual, Century Dynamics Inc., 2001.

[9] DH Lassila, WP Waiters, DJ Nikkel, Jr., RP Kershaw, Analysis Of Soft Recovered Shaped Charge Jet Particles, Symp. Structures Under Extreme Loading Conditions at 1996 ASMEs Pressure Vessels and Piping Conference, Montreal, Canada July 21-26, 1996 (Lawrence Livermore National Lab USA, Report No. UCRL-JC-123850 Apr 1996). https://doi.org/10.2172/251380

[10] Steven M Buc, Liner materials: resources, processes, properties, costs and applications, SPC91-282-2, DARPA, Viginia, USA, 1991. 